\title{
Visual Development of Healthy Full-Term Infants under 24 Months of Age Using the Preverbal Visual Assessment Questionnaire
}

\author{
Eunhee Kim $^{a}$ JungSoo Lee ${ }^{b}$ Hae-Yeon Park ${ }^{c}$ Jungjae Lee ${ }^{d}$ Mee-Gang Kim ${ }^{\text {e }}$ \\ Joo Hyun Parkc
}

\begin{abstract}
${ }^{a}$ Department of Pediatrics, Areumdri Pediatric Clinic, Gyeonggi-do, Republic of Korea; ${ }^{b}$ Department of Rehabilitation Medicine, Daejeon St. Mary's Hospital, College of Medicine, The Catholic University of Korea, Daejeon, Republic of Korea; 'Department of Rehabilitation Medicine, Seoul St. Mary's Hospital, College of Medicine, The Catholic University of Korea, Seoul, Republic of Korea; 'Department of Rehabilitation Medicine, Seosong Hospital, Incheon, Republic of Korea; 'Department of Rehabilitation Medicine, Yeouido St. Mary's Hospital, College of Medicine, The Catholic University of Korea, Seoul, Republic of Korea
\end{abstract}

\section{Keywords}

Visual development - Visual cognitive function - Visual assessment · Questionnaire · Healthy infants · Full-term infants

\begin{abstract}
As visual perception development proceeds rapidly after birth, early detection of developmental maturity is required. Healthy infants do not have many opportunities for visual perception evaluation, so a reliable evaluation method is necessary. This retrospective study included 276 healthy fullterm infants $<24$ months of age using the Preverbal Visual Assessment (PreViAs) questionnaire, which measures scores of subdivided age-groups for the global scores and 4 domains: visual attention (VA), visual communication (VC), visual-motor coordination (VMC), and visual processing (VP). Through this study, reference values and cutoff scores of the PreViAs questionnaire were presented, reliability was secured, and potential influencing factors of the PreViAs scores were analyzed. Using Cronbach's a coefficient, the global scores were $0.938,0.781$ for VA, 0.660 for VC, 0.874 for VMC, and 0.942 for VP. The internal consistency of the question-
\end{abstract}

karger@karger.com www.karger.com/dne

Karger"

BOPEN ACCESS
C 2021 The Author(s).

Published by S. Karger AG, Basel

This is an Open Access article licensed under the Creative Commons Attribution-NonCommercial-4.0 International License (CC BY-NC) (http://www.karger.com/Services/OpenAccessLicense), applicable to the online version of the article only. Usage and distribution for commercial purposes requires written permission. naire was high in the global scores and 3 domains (VA, VMC, and VP). In infants under 12 months, the global scores and the VA, VMC, and VP domains showed positive association with gestational age, whereas the VC domain correlated with sex: which was found to be greater for females $(p<$ 0.05). In those 12 month and above, no clinical factors were significantly associated with the PreViAs scores in all domains. The PreViAs questionnaire is a useful tool for visual assessment of healthy full-term infants under 24 months of age, suggesting reference values and cutoff scores according to age, and estimating the maturation age for visual perception development of each domain.

(c) 2021 The Author(s).

Published by S. Karger AG, Basel

\section{Introduction}

Visual perception plays an important role in cognitive, social, and behavioral development as it undergoes rapid development throughout infancy $[1,2]$. Evaluation of visual perceptual development reflects not only visual acuity and visual field loss but also behavioral and cogni- 
tive development disorders. However, the evaluation of infant visual development cannot independently evaluate sensory, cognitive, and visual-motor abilities [1]. Therefore, it is essential to additionally perform neurodevelopment assessment to detect potential visual abnormalities during infancy. Early visual assessment has been shown to effectively measure the plasticity of neural development, which has informed the intervention in pre-existing injury and the prediction of future neurological ability [2].

The tests for visual evaluation during the preverbal period are scarce, and neurodevelopmental assessment rarely shows abnormalities in healthy full-term infants. Therefore, in healthy full-term infants with potential issues of visual development, the opportunities to predict visual impairment early and receive treatment may easily be missed. Also, in most cases, vaccinations and regular checkups are performed at private pediatrics that do not conduct specialized eye examination. As such, an appropriate assessment protocol in pediatric clinics may be helpful in the early prediction and treatment of visual perceptual development problems.

Currently, only a number of assessment tools are commonly practiced for evaluating children's visual function. Among these, preferential looking has been used as an appropriate tool to measure the visual acuity of infants and toddlers [3]. In particular, Wallace's preferred practice pattern is another good example of standard vision screening guidelines in childhood [4]. However, such assessments focus on providing information about the vision and the anatomical state of the visual system and cannot ascertain visual cognitive function. Therefore, a comprehensive assessment tool for visual development is needed [3, 4]. The Marianne Frostig Developmental Test is an assessment tool for visual perception, which has been used for over 50 years, and is a general test that has been revised and updated to the present cultural changes. However, it is not applicable to preverbal infants as it is recommended for children between 3 and 9 years of age $[5,6]$. A test battery of child development for examining functional vision, developed by Atkinson, is one of the methods of evaluating functional visual abilities of normal full-term infants prior to age 4 , and is used to assess various perceptual, motor, spatial, and cognitive abilities [1]. This tool includes an assortment of tests for preverbal and verbal infants under 4 years of age to evaluate visual perception; however, it can only be utilized by experienced professional examiners, making it difficult to include as a common screening test for the majority of healthy preverbal full-term infants.
Among the assessments mentioned, there are also pediatric eye questionnaires proposed by clinicians for normal or visually impaired children, but these are mainly for children over 2 years of age and focus on visual acuity without evaluating visual perception. Additionally, while parental questionnaires are useful tools to assess and monitor children's development, no questionnaire has proven its accuracy to perform a reliable vision screening. Therefore, it was considered necessary to develop and verify a structured questionnaire for visual perception assessment of healthy preverbal infants.

The Preverbal Visual Assessment (PreViAs) questionnaire, designed by Pueyo et al. [7] is an effective tool for the assessment of visual integrative functions and early detection of abnormal visual behavior in infants under 24 months of age $[7,8]$. The questionnaire has proven to be reliable and provides normative data on specific areas of visual cognitive behavior in age subgroups. A recent study comparing visual maturity between high-risk preterm infants and full-term infants $<12$ months of age showed the PreViAs questionnaire to be a useful tool for visual evaluation [9].

This study was conducted to use the PreViAs questionnaire in healthy full-term infants under 24 months of age to establish a standard for normal development of visual domains by age-group. Through this, we attempted to determine reference values, cutoff scores, reliability of evaluation, and potential influencing factors of PreViAs questionnaire scores.

\section{Methods}

\section{The PreViAs Questionnaire}

The PreViAs questionnaire was originally designed in Spanish and was published in its English version by Pueyo et al [7]. The questionnaire used in this study is the English version. The PreViAs questionnaire consists of 30 simple yes/no questions about the infant's visual development. Each question is related to 1 or more of the following 4 cognitive domains: visual attention (VA), visual communication (VC), visual - motor coordination (VMC), and visual processing (VP) [10]. Scores were calculated as 1 point for each positive response and 0 for a negative response. Each domain's score is the sum of all positive responses. Some items belong to multiple domains: for example, questions 8 and 9 belong to the $\mathrm{VA}, \mathrm{VMC}$, and VP domains. The maximum total scores a patient can achieve on the questionnaire is 30 points (accounting for overlap in domains: 11 points in VA, 5 points in VC, 13 points in VMC, and 20 points in VP) (Table 1 ).

\section{Study Design and Subjects}

This retrospective study was conducted on the medical records of 305 infants and excluded those born prematurely or with ophthalmic diseases. Resultantly, the study included the records of 276
Kim/Lee/Park/Lee/Kim/Park 
Table 1. The PreViAs questionnaire

\begin{tabular}{|c|c|c|}
\hline \multicolumn{2}{|c|}{ Questions } & \multirow{2}{*}{$\begin{array}{l}\text { Domain } \\
\text { VA }\end{array}$} \\
\hline 1 & Is your child interested in lights and fixes the eyes on them? & \\
\hline 3 & Is he/she able to look toward a sound source? & VA \\
\hline 5 & $\begin{array}{l}\text { Does he/she follow the movement of a nearby object moving } \\
\text { slowly horizontally and vertically? }\end{array}$ & VA, VMC \\
\hline 6 & Does your child observe his/her own hands? & VA, VMC, VP \\
\hline 7 & Does he/she try to reach for toys or objects with his/her hands? & VA, VMC \\
\hline 10 & Does he/she look in a mirror? & VA, VC \\
\hline 11 & Does he/she look at the pictures of a storybook? & VA, VP \\
\hline 12 & $\begin{array}{l}\text { Does your child smile when his/her mother or father gets close } \\
\text { without making any sound? }\end{array}$ & VC \\
\hline 13 & Does your child smile to people who approach him/her smiling? & VC \\
\hline 14 & Does he/she imitate gestures or greetings? & $\mathrm{VC}, \mathrm{VP}$ \\
\hline 15 & $\begin{array}{l}\text { Does he/she react to strangers by staring at them or being } \\
\text { embarrassed? }\end{array}$ & VC \\
\hline 19 & $\begin{array}{l}\text { Does he/she know where things that interest him/her are kept at } \\
\text { home, such as his/her toys, books, clothing or food? }\end{array}$ & VMC, VP \\
\hline 20 & Does your child scribble with a pencil or a pen on paper? & VMC, VP \\
\hline 21 & Does he/she imitate painting some strokes? & VMC, VP \\
\hline 22 & Does he/she know where his/her hands, ears, mouth, eyes, ... are? & VMC, VP \\
\hline 23 & Does he/she recognize familiar objects or people? & VP \\
\hline 24 & $\begin{array}{l}\text { Does your child react in advance to common situations, such as } \\
\text { knowing he/she will eat or go to the street when he/she sees the } \\
\text { baby trolley? }\end{array}$ & VP \\
\hline 25 & Does he/she look at a known person if named? & VP \\
\hline 26 & $\begin{array}{l}\text { Does he/she look for what turn things on like a toy switch, light } \\
\text { switch, ...? }\end{array}$ & VP \\
\hline 27 & Does he/she recognize himself in a photo? & VP \\
\hline 28 & Does he/she identify several drawings (like animals, a house, ...)? & VP \\
\hline
\end{tabular}

Visual Development of Healthy Full-

Term Infants 
Table 1 (continued)

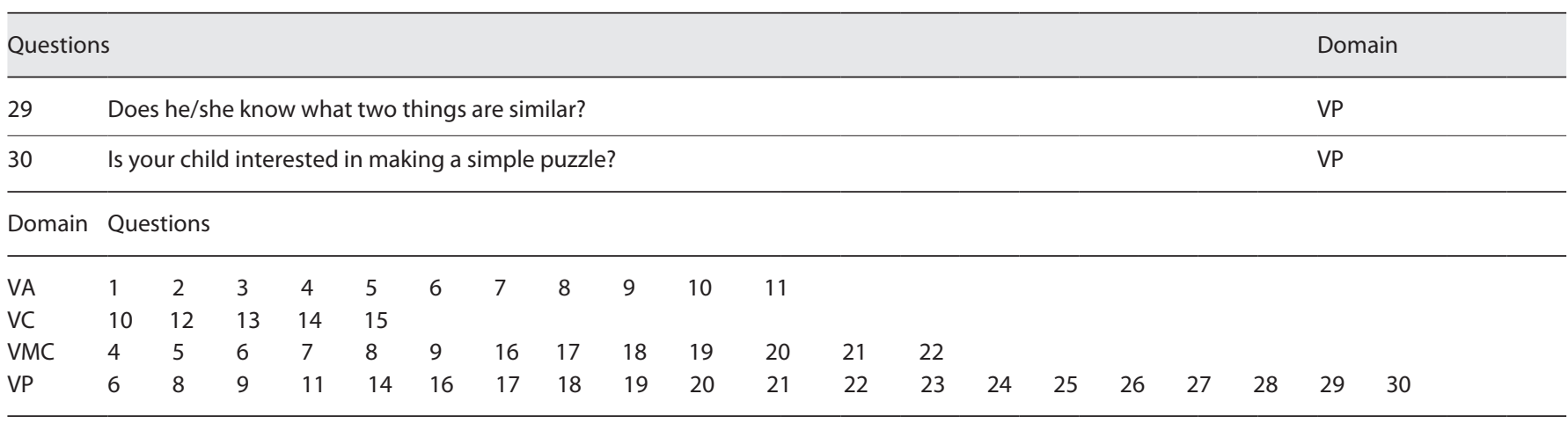

Reused from the article of García-Ormaechea et al. [8] with original copyright holder's permission. VA, visual attention; VC, visual communication; VMC, visualmotor coordination; VP, visual processing; PreViAs, Preverbal Visual Assessment.

healthy full-term infants under 24 months of age who received vaccinations and regular checkups at a private pediatrics, from September 2018 to October 2019. Questionnaires were administered by clinicians who asked each question to the infant's parent or primary caregiver and scored their responses accordingly. This direct inquiry approach helped improve the completeness of the questionnaire. This study was approved by the appropriate Institutional Review Board, and adhered to the tenets of the Declaration of Helsinki. We analyzed the reliability of the PreViAs questionnaire in healthy full-term infants, and established reference values and cutoff scores for each domain of the 4 subdivided agegroups: 0 months $<$ group $1 \leq 6$ months, 6 months $<$ group $2 \leq 12$ months, 12 months < group $3 \leq 18$ months, and 18 months < group $4 \leq 24$ months. The subjects were divided into 2 groups at 12 -month intervals to analyze the correlations according to age, gestational age, birth weight, presence of siblings (no: 0 , yes: 1 ), and sex (male: 0 , female: 1 ).

In addition, as pertains to this study, maturation age is defined as the age at which the development of a given visual domain is completed. The maturation age of visual perception development was estimated by analyzing the values of the first quartile, median, and the third quartile of the PreViAs scores in each visual domain.

\section{Statistical Analysis}

Data are presented as estimated mean \pm standard deviation. Internal consistency was assessed using Cronbach's a coefficient which estimates the reliability of the scores for global and all domains. Cronbach's a value of $>0.7$ was considered acceptable for internal consistency.

The multivariable linear regression analysis was performed to assess the relationship between PreViAs scores and independent variables including age, gestational age, birth weight, presence of siblings, and sex, and the $p$ value of $<0.05$ was considered statistically significant. The PreViAs scores in each domain were analyzed by Kruskal-Wallis test to estimate maturation age of visual perception development. All statistical tests were performed using the SPSS (Statistical Package for the Social Sciences) for Mac OS (ver $25.0 \mathrm{~K}$, IBM, Armonk, NY, USA).
Table 2. Clinical characteristics of the infants

\begin{tabular}{ll}
\hline Variable & Full-term $(N=276)$ \\
\hline Gender & \\
$\quad$ Male & $137(49.6)$ \\
$\quad$ Female & $139(50.4)$ \\
Infants with identified siblings & $254(92.0)$ \\
With siblings & $174(63.0)$ \\
Without siblings & $80(29.0)$ \\
Chronological age, days & $373.5 \pm 210.4$ \\
Gestational age, weeks & $38.7 \pm 1.0$ \\
Birth weight, kg & $3.3 \pm 0.4$ \\
\hline
\end{tabular}

Data are expressed as mean \pm SD or $n(\%) . N$, number of infants; $\mathrm{SD}$, standard deviation.

\section{Results}

\section{Demographic Data}

In total, the medical records of 276 subjects were reviewed for this study, to include 137 (49.6\%) males and 139 (50.4\%) females. The mean age was $373.5 \pm 210.4$ days. Gestational age at birth was $38.7 \pm 1.0$ weeks and mean birth weight was $3.3 \pm 0.4 \mathrm{~kg}$. Of the 254 subjects for whom siblings were confirmed, 174 had siblings and 80 had no siblings. Table 2 summarizes the demographic data. Three of the subjects included in the study had brain ultrasonography due to their larger-than-average head circumference, but the results were normal, and none of them had brain MRI. Sixteen subjects were the product of artificial insemination, and 260 of natural conception. Four infants with a diagnosis of jaundice, 2 with heart disease, 1 with cephalhematoma, 1 with hydrocele, 1 with 
Table 3. The internal consistency of the PreViAs questionnaire by Cronbach's a coefficient

\begin{tabular}{|c|c|c|c|}
\hline & Item No. & Items, $n$ & Cronbach's a \\
\hline Global & $1,2,3,4,5,6,7,8,9,10,11,12,13,14,15,16,17,18,19,20,21,22,23,24,25,26,27,28,29,30$ & 30 & 0.938 \\
\hline VA & $1,2,3,4,5,6,7,8,9,10,11$ & 11 & 0.781 \\
\hline VMC & $4,5,6,7,8,9,16,17,18,19,20,21,22$ & 13 & 0.874 \\
\hline VP & $6,8,9,11,14,16,17,18,19,20,21,22,23,24,25,26,27,28,29,30$ & 20 & 0.942 \\
\hline
\end{tabular}

VA, visual attention; VC, visual communication; VMC, visual-motor coordination; VP, visual processing; PreViAs, Preverbal Visual Assessment.

Table 4. The mean score and cutoff score of the PreViAs questionnaire for each age-group

\begin{tabular}{|c|c|c|c|c|}
\hline & $\begin{array}{l}\text { Group } 1 \\
0-6 \text { months } \\
(N=99)\end{array}$ & $\begin{array}{l}\text { Group } 2 \\
6-12 \text { months } \\
(N=75)\end{array}$ & $\begin{array}{l}\text { Group } 3 \\
12-18 \text { months } \\
(N=54)\end{array}$ & $\begin{array}{l}\text { Group } 4 \\
18-24 \text { months } \\
(N=48)\end{array}$ \\
\hline \multicolumn{5}{|l|}{ Global score } \\
\hline Mean (SD) & $15.16(4.04)$ & $23.27(2.66)$ & $27.37(2.85)$ & $29.33(0.81)$ \\
\hline Mean-2SD & 7.08 & 17.95 & 21.67 & 27.71 \\
\hline \multicolumn{5}{|l|}{ VA } \\
\hline Mean (SD) & $9.81(1.73)$ & $10.97(0.16)$ & $11.00(0.00)$ & $11.00(0.00)$ \\
\hline Mean-2SD & 6.35 & 10.65 & 11.00 & 11.00 \\
\hline \multicolumn{5}{|l|}{ VC } \\
\hline Mean (SD) & $3.32(1.10)$ & $4.73(0.55)$ & $4.96(0.19)$ & $4.98(0.14)$ \\
\hline Mean-2 SD & 1.12 & 3.63 & 4.58 & 4.70 \\
\hline \multicolumn{5}{|l|}{ VMC } \\
\hline Mean (SD) & $6.21(2.00)$ & $10.05(1.21)$ & $11.74(1.32)$ & $12.60(0.49)$ \\
\hline Mean-2 SD & 2.21 & 7.63 & 9.10 & 11.62 \\
\hline \multicolumn{5}{|l|}{ VP } \\
\hline Mean (SD) & $6.33(2.89)$ & $13.36(2.60)$ & $17.37(2.85)$ & $19.35(0.79)$ \\
\hline Mean-2 SD & 0.55 & 8.16 & 11.67 & 17.77 \\
\hline
\end{tabular}

The cutoff score is 2 SDs below the mean. VA, visual attention; VC, visual communication; VMC, visual-motor coordination; $\mathrm{VP}$, visual processing; $N$, number of infants; SD, standard deviation.

umbilical hernia, and 1 with infection following birth, but all responded favorably to treatment.

\section{Reliability for Visual Domains of the PreViAs \\ Questionnaire}

Cronbach's a coefficient was 0.938 for global 30 items, 0.781 for VA, 0.660 for VC, 0.874 for VMC, and 0.942 for VP (Table 3). The internal consistency of the questionnaire was high in the global scores and 3 domains (VA, VMC, and VP), but somewhat low in the $\mathrm{VC}$ domain.

\section{The PreViAs Questionnaire Scores}

Table 4 summarizes the mean and cutoff scores of the PreViAs questionnaire for each age-group. Group 1's ref- erence values (mean scores) were 15.16, 9.81, 3.32, 6.21, and 6.33 in global, VA, VC, VMC, and VP domains, respectively. In group 2, the reference values were 23.27 (global), 10.97 (VA), 4.73 (VC), 10.05 (VMC), and 13.36 (VP). The reference values of group 3 were 27.37 (global), 11.00 (VA), 4.96 (VC), 11.74 (VMC), and 17.37(VP). In group 4, the reference values were 29.33 (global), 11.00 (VA), 4.98 (VC), 12.60(VMC), and 19.35 (VP).

Cutoff scores (mean-2 standard deviation) for group 1 were $7.08,6.35,1.12,2.21$, and 0.55 in the global, VA, VC, VMC, and VP domains, respectively. The cutoff score for group 2 were 17.95 (global), 10.65 (VA), 3.63 (VC), 7.63 (VMC), and 8.16 (VP). The cutoff scores of group 3 were 21.67 (global), 11.00 (VA), 4.58 (VC), 9.10 (VMC), and 11.67 (VP). In group 4, cutoff scores were 
Table 5. Multiple linear regression model to predict the PreViAs questionnaire scores

\begin{tabular}{|c|c|c|c|c|}
\hline & \multicolumn{2}{|c|}{ Before 12 months } & \multicolumn{2}{|c|}{ After 12 months } \\
\hline & estimate (SD) & $p$ value & estimate (SD) & $p$ value \\
\hline \multicolumn{5}{|l|}{ Global } \\
\hline Gestational age & $1.28(0.43)$ & $0.004^{*}$ & $0.03(0.24)$ & 0.89 \\
\hline Birth weight & $0.36(0.54)$ & 0.51 & $0.06(0.37)$ & 0.88 \\
\hline Siblings & $-1.39(0.94)$ & 0.14 & $-0.23(0.55)$ & 0.69 \\
\hline Sex (ref; male) & $1.78(0.90)$ & 0.05 & $0.11(0.53)$ & 0.83 \\
\hline$R^{2}$ & 9.17 & 0.00 & 0.00 & $<0.001 *$ \\
\hline \multicolumn{5}{|l|}{ VA } \\
\hline Gestational age & $0.32(0.12)$ & $0.01^{*}$ & $0.00(0.00)$ & 0.75 \\
\hline Birth weight & $0.19(0.15)$ & 0.21 & $0.00(0.00)$ & 0.85 \\
\hline Siblings & $-0.36(0.26)$ & 0.17 & $0.00(0.00)$ & 0.59 \\
\hline Sex (ref; male) & $0.38(0.25)$ & 0.13 & $0.00(0.00)$ & 0.49 \\
\hline$R^{2}$ & 9.61 & 0.00 & 50.18 & $<0.001^{*}$ \\
\hline \multicolumn{5}{|l|}{ VC } \\
\hline Gestational age & $0.18(0.09)$ & 0.06 & $-0.01(0.02)$ & 0.46 \\
\hline Birth weight & $0.15(0.12)$ & 0.22 & $0.01(0.03)$ & 0.68 \\
\hline Siblings & $-0.17(0.20)$ & 0.40 & $-0.05(0.04)$ & 0.18 \\
\hline Sex (ref: male) & $0.53(0.20)$ & $0.009 *$ & $0.01(0.04)$ & 0.98 \\
\hline$R^{2}$ & 9.51 & 0.00 & 0.02 & 0.66 \\
\hline \multicolumn{5}{|l|}{ VMC } \\
\hline Gestational age & $0.61(0.21)$ & $0.00 *$ & $0.01(0.11)$ & 0.93 \\
\hline Birth weight & $0.25(0.26)$ & 0.34 & $0.06(0.17)$ & 0.29 \\
\hline Siblings & $-0.55(0.45)$ & 0.23 & $-0.09(0.25)$ & 0.73 \\
\hline Sex (ref; male) & $0.74(0.44)$ & 0.09 & $-0.06(0.24)$ & 0.80 \\
\hline$R^{2}$ & 10.32 & 0.00 & 0.40 & 0.98 \\
\hline \multicolumn{5}{|l|}{ VP } \\
\hline Gestational age & $1.06(0.36)$ & $0.004^{*}$ & $0.03(0.24)$ & 0.92 \\
\hline Birth weight & $0.14(0.45)$ & 0.76 & $0.06(0.37)$ & 0.88 \\
\hline Siblings & $-1.09(0.78)$ & 0.17 & $-0.22(0.55)$ & 0.70 \\
\hline Sex (ref; male) & $1.34(0.75)$ & 0.08 & $0.13(0.53)$ & 0.80 \\
\hline$R^{2}$ & 10.62 & 0.00 & 0.25 & 0.99 \\
\hline
\end{tabular}

VA, visual attention; VC, visual communication; VMC, visual-motor coordination; VP, visual processing; $R^{2}, R$ squared, coefficient of determination; SD, standard deviation; ref, reference; PreViAs, Preverbal Visual Assessment. $* p<0.05$ is considered statistically significant.

27.71 (global), 11.00 (VA), 4.70 (VC), 11.62 (VMC), and 17.77 (VP).

\section{Potential Influencing Factors of PreViAs \\ Questionnaire Scores}

A total of 276 infants were divided into 2 groups: below-12-months and above-12-months groups. Controlling for age, gestational age, birth weight, presence of siblings, and sex, the potential influencing factors of PreViAs scores were detected via a multiple linear regression model. In infants under 12 months, the global scores and the VA, VMC, and VP domains showed positive association with gestational age, whereas the VC domain corre- lated with sex, which was found to be greater for females $(p<0.05)$. In those infants who are 12 months and above, no clinical factors were significantly associated with PreViAs scores in all domains. Detailed information is presented in Table 5.

\section{Maturation Age of Each PreViAs Domain}

Our analysis found the maturation age for visual perception development to be 6 months for VA, 12 months for VC, 24 months for VMC, and 21 months for VP. Figure 1 shows the timing of development completion through PreViAs scores for each domain by age. 


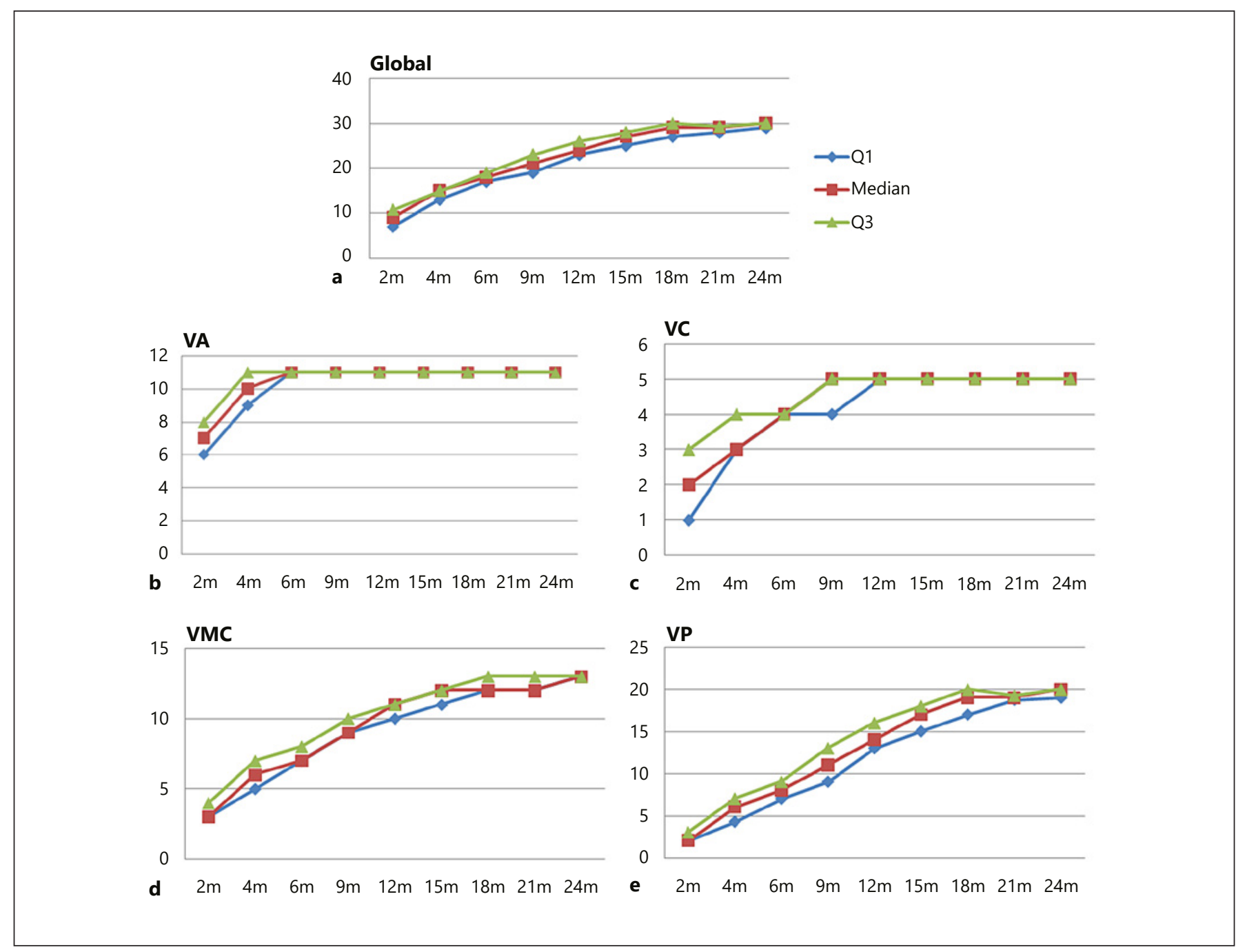

Fig. 1. The scores of the PreViAs questionnaire for age in each visual domain. Figures represent the first quartile (Q1), median, and the third quartile (Q3) values. Global score (a), VA (b), VC (c), VMC (d), VP (e). PreViAs, Preverbal Visual Assessment; VA, visual attention; VC, visual communication; VMC, visual-motor coordination; $\mathrm{VP}$, visual processing.

\section{Discussion}

Visual impairment interferes with neurocognitive development in children across a wide range of areas, such as communication skills, learning processes, attention, memory, motor skills, spatial sensory cognition, and other cognitive abilities [10-12]. The first year of life is the most critical period for visual development [13]. Therefore, early detection of abnormal visual maturation can establish appropriate treatment and initiate visual stimulation strategies. However, the evaluation of visual perception development in most healthy children is limited to identifying vision-related eye contact, eye movement, corneal opacity, strabismus, focusing, and genetic disorders. In addition, vision and visual acuity assessment is typically performed after the age of 3 years.

Visual perceptual maturation occurs primarily during the first few months of life, and fully at 2 years of age, normally resulting in 20/20 vision on the preferential looking test [14]. Based on Goodale et al. [15], the visual pathways are divided into ventral and dorsal streams. The integration of the ventral (or "vision-for-perception" pathway) and dorsal (or "vision-for-action" pathway) streams are one of the most fundamental principles of visual processing in the brain $[16,17]$. It is known that to optimize integration of the ventral and dorsal streams, detection and 
management of visual developmental delay should be made before age 2 [8]. Therefore, it is recommended that infants younger than 2 years undergo a developmental visual assessment. However, infants at that age are commonly unable to pay attention to the examination. Therefore, special tests such as visual evoked potential and MRI may be performed, which are not always effective in confirming the integration of the ventral and dorsal streams $[2,8,18]$. In addition, these tests are mainly applied to premature infants and infants with underlying medical conditions. Although it is not difficult to apply to healthy full-term infants, it is not clinically feasible due to requiring sedation and the low overall cost-efficiency for such visual developmental screening.

There are not many evaluations of children's visual function using questionnaires, but there have been studies focusing on visual skills through structured clinical history-taking tools $[1,19,20]$. While there are a few tools to assess overall visual integration function in healthy infants; however, there are some studies that score for visual integration function or provide a normal reference value for each age [7]. Therefore, a verified tool for visual behavior assessment that does not require a long time would be helpful to easily screen preverbal infants. The PreViAs questionnaires published in 2014, is a useful tool for scoring and assessing visual integration and is effective in early detection of abnormal visual maturity in infants under 24 months of age [7, 8]. Accordingly, this study reviewed the visual assessment records of private pediatrics using the PreViAs questionnaire, in 276 healthy full-term infants under 24 months. This was to confirm the reliability of the PreViAs questionnaire as a tool to assess overall visual perception development.

The internal consistency of the global scores and VA, $\mathrm{VMC}$, and VP domains were high but low in the VC domain. Since the number of items in the VC domain is smaller than that of other domains, it can be inferred that these results were potentially compromised. Also, since the PreViAs questionnaire is a visual perception assessment tool designed in Spain, it may be relevant to take into account cross-country and cultural differences.

In the research done by Pueyo et al. [7], the subjects were divided into 2 or 3 -month intervals, while we divided the subjects in this study into 6-month intervals. Thus, the reference values and cutoff scores for all domains of Pueyo et al. [7] do not match our results. That is, the cross-review values between these studies are difficult to compare, given the differences between respective age classification groupings, and the differences in the infant's environments. However, we think this will be one of several attempts to establish a global standard for determining whether or not an infant displays abnormality in their visual perceptual development.

Various factors influence development, and among them, birth weight and gestational age are known to be important factors in early infants $[21,22]$. There have been studies on the differences in motor activity, sensory processes, and behavioral and cognitive development according to birth weight and gestational age [22, 23]. However, most of these studies are on preterm infants, and there are few studies on visual development according to gestational age and birth weight of healthy full-term infants. In a recent study by Lee et al. [9] as a result of analyzing PreViAs scores of preterm and full-term infants under 12 months of age, gestational age and birth weight were correlated with visual perceptual development in preterm infants. Referring to this previous study, our research was conducted to assess the association of potential influencing factors affecting PreViAs scores in healthy full-term infants. Gestational age was positively associated with PreViAs scores for global, VA, VMC, and VP domains in the below-12-months group $(p<0.05)$. This is a very interesting result, which means future studies should further investigate potential influencing factors related to the visual development of full-term infants. However, there were no significant factors in all visual domains in the after 12-month group. In healthy fullterm infants, we can assume that maturity in visual development was reached naturally after 12 months regardless of several factors. It is expected that additional studies will be conducted in this regard.

According to Colombo's study of visual development, visual attention for most healthy infants is known to mature in the first year of birth [24]. However, in the case of healthy infants, the overall ability of attention, movement, communication, processing, etc., develops in an integrated way. There are less than a handful of studies that specify maturation periods of visual perceptual development $[2,24]$. Our study compensated this lack in research and our analysis found that maturation was essentially completed at 6 months for the VA, 12 months for the VC, and 24 months for the VMC, and 21 months for the VP domains. In particular, the VA and VC domains develop rapidly and complete before 12 months; while the VMC and VP domains develop considerably before 12 months, reaching maturity at 24 months (Fig. 1). This was consistent with Goodale et al. [15] model of integrating the ventral and dorsal streams.

The limitations of this study are as follows. First, we used the English version of the PreViAs questionnaire. In 
the process of translating English to administer the questionnaire, the original text or the author's original intention may not have been sufficiently reflected. We have taken into account cultural, emotional, social, and environmental differences, but acknowledge biases may exist. Therefore, we plan to develop and standardize a Korean version of the questionnaire in the future. Second, the number of study subjects by age was unequal. This study was conducted on infants who visited clinics at the time of vaccination, and there was a limit to balancing the number of infants in each group. Future studies of larger sample sizes are expected to ameliorate this imbalance.

The PreViAs questionnaire may raise questions regarding objectivity, due to the reliability of the evaluation itself and attitudes of the primary caregivers toward the visual perceptual development of infants. In addition, the completion of the questionnaire differed according to the reading, language, and cognitive impairments of the primary caregiver who responded to the questionnaire [7], and the primary caregiver may bias toward subjective evaluations in contrast to expert assessments. Nevertheless, there is strong evidence that, in most cases, caregivers make relatively accurate judgments about whether their infants perform certain behaviors [25-27]. In this study, clinicians implemented questionnaires during immunizations or regular checkups, asked parents or primary caregivers each question and scored responses to increase the objectivity of the questionnaire. Therefore, the respondents were able to complete the questionnaire easily and conveniently without any special difficulties. In conclusion, the reliability of the PreViAs questionnaire was confirmed, and it is a useful tool for the visual perception evaluation of healthy full-term infants under 24 months of age and significant reference values and cutoff scores for each age can be presented.

\section{Statement of Ethics}

This article was reviewed and approved by the Institutional Review Board (IRB) of the Catholic Medical Center, the Catholic University of Korea (Protocol Number: MC19QISI0147), and a written consent requirement was waived. Since this study is a retrospective medical record study, it is a study within the minimum risk in that it does not harm the research subject, and the subject information is anonymized, so the contents that can identify the subject's identity are not collected, and the personal information is kept confidential.

\section{Conflict of Interest Statement}

The authors have no conflicts of interest to disclose.

\section{Funding Sources}

This research did not receive any specific grant from funding agencies in the public, commercial, or not-for-profit sectors.

\section{Author Contributions}

Eunhee Kim contributed to conceptualization, methodology, and writing - original draft. JungSoo Lee contributed to data analysis, visualization, and editing. Hae-Yeon Park contributed to software, visualization, and writing - review. Jungjae Lee contributed to resources and data curation. Mee-Gang Kim contributed to writing - review and editing and investigation. Joo Hyun Park contributed to supervision and project administration.

\section{Data Availability Statement}

All data generated or analyzed during this study are included in this article. Further inquiries can be directed to the corresponding author.

\section{References}

1 Atkinson J, Anker S, Rae S, Hughes C, Braddick O. A test battery of child development for examining functional vision (ABCDEFV). Strabismus. 2002 Dec;10(4):245-69.

2 Braddick O, Atkinson J. Development of human visual function. Vision Res. 2011 Jul 1; 51(13):1588-609.

3 Lewis TL, Maurer D. Preferential looking as a measure of visual resolution in infants and toddlers: a comparison of psychophysical methods. Child Dev. 1986 Aug;57(4):106275.

4 Wallace DK, Morse CL, Melia M, Sprunger DT, Repka MX, Lee AK, et al. Pediatric eye evaluations preferred practice pattern ${ }^{\circ}$ : I. Vi- sion screening in the primary care and community setting; II. Comprehensive ophthalmic examination. Ophthalmology. 2018 Jan; 125(1):184-227.

5 Maslow P, Frostig M, Lefever DW, Whittlesey JRB. The Marianne Frostig Developmental Test of Visual Perception, 1963 Standardization. Percept Mot Skills. 1964 Oct;19(2):46399.

6 Natalia MYA, Azwar S. Development of visual perception test for children aged 3-8 years. Res Soc Develop. 2020;9(10):14.

7 Pueyo V, Garcia-Ormaechea I, Gonzalez I, Ferrer C, de la Mata G, Dupla M, et al. Development of the preverbal visual assessment
(PreViAs) questionnaire. Early Hum Dev. 2014 Apr;90(4):165-8.

8 Garcia-Ormaechea I, Gonzalez I, Dupla M, Andres E, Pueyo V. Validation of the preverbal visual assessment (PreViAs) questionnaire. Early Hum Dev. 2014 Oct;90(10):635-8.

9 Lee J, Kim MG, Park HY, Nam KE, Park JH. Visual assessment of preterm and full-term infants under the age of 12 months using the preverbal visual assessment questionnaire. Early Hum Dev. 2021 Feb;153:105289.

10 Leung MP, Thompson B, Black J, Dai S, Alsweiler JM. The effects of preterm birth on visual development. Clin Exp Optom. 2018 Jan; 101(1):4-12.
Visual Development of Healthy FullTerm Infants
Dev Neurosci 2022;44:39-48 DOI: $10.1159 / 000520935$ 
11 Cass HD, Sonksen PM, McConachie HR. Developmental setback in severe visual impairment. Arch Dis Child. 1994 Mar;70(3):192-6.

12 Kran BS, Lawrence L, Mayer DL, Heidary G. Cerebral/cortical visual impairment: a need to reassess current definitions of visual impairment and blindness. Semin Pediatr Neurol. 2019 Oct;31:25-9.

13 Hyvarinen L, Walthes R, Jacob N, Chaplin $\mathrm{KN}$, Leonhardt $\mathrm{M}$. Current understanding of what infants see. Curr Ophthalmol Rep. 2014; 2(4):142-9.

14 Greenwald MJ. Visual development in infancy and childhood. Pediatr Clin North Am. 1983;30(6):977-93.

15 Goodale MA, Milner AD. Separate visual pathways for perception and action. Trends Neurosci. 1992 Jan;15(1):20-5.

16 David Milner A. MAG. the visual brain in action. Oxford: Oxford University Press; 1995.

17 Hebart MN, Hesselmann G. What visual information is processed in the human dorsal stream? J Neurosci. 2012 Jun;32(24):8107-9.
18 Braddick O, Atkinson J, Wattam-Bell J. Normal and anomalous development of visual motion processing: motion coherence and "dorsal-stream vulnerability. Neuropsychologia. 2003;41(13):1769-84.

19 Katsumi O, Chedid SG, Kronheim JK, Henry RK, Jones CM, Hirose T. Visual ability score: a new method to analyze ability in visually impaired children. Acta Ophthalmol Scand. 1998 Feb;76(1):50-5.

20 McCulloch DL, Mackie RT, Dutton GN, Bradnam MS, Day RE, McDaid GJ, et al. A visual skills inventory for children with neurological impairments. Dev Med Child Neurol. 2007 Oct;49(10):757-63.

21 Marta M, Beata U, Beata C, Monika O, Alina B. An influence of birth weight, gestational age, and Apgar score on pattern visual evoked potentials in children with history of prematurity. Neural Plast. 2015;2015:754864.
22 Simone VG, Teresa AM, Alison T, Elizabeth GM. Birth and developmental correlates of birth weight in a sample of children with potential sensory processing disorder. BMC Pediatr. 2013 Feb;13:29.

23 Hutton JL, Pharoah PO. Effects of cognitive, motor, and sensory disabilities on survival in cerebral palsy. Arch Dis Child. 2002;86:84-9.

24 Colombo J. The development of visual attention in infancy. Annu Rev Psychol. 2001;52: 337-67.

25 JaneSquires NK, Bricker D. Use of parentcompleted developmental questionnaires for child-find and screening. Infants and Young Children. 1990;3(2):46-57.

26 KarenDiamond EJS. The role of parental report in the screening and assessment of young children. J Early Interven. 1993;17(2):107-15.

27 Glascoe FP, Dworkin PH. The role of parents in the detection of developmental and behavioral problems. Pediatrics. 1995 Jun;95(6): $829-36$. 